\title{
Memória na Justiça: A mobilização dos direitos humanos e a construção da memória da ditadura no Brasil
}

Memory Through Justice: The Mobilisation of Human Rights and the Construction of the Memory of the Dictatorship in Brazil

Mémoire dans la justice : la mobilisation des droits humains et la construction de la mémoire de la dictature au Brésil

\section{Cecília MacDowell Santos}

\section{OpenEdition}

\section{Journals}

Edição electrónica

URL: http://journals.openedition.org/rccs/1719

DOI: $10.4000 /$ rccs. 1719

ISSN: 2182-7435

\section{Editora}

Centro de Estudos Sociais da Universidade de Coimbra

\section{Edição impressa}

Data de publição: 1 março 2010

Paginação: 127-154

ISSN: 0254-1106

Refêrencia eletrónica

Cecília MacDowell Santos, « Memória na Justiça: A mobilização dos direitos humanos e a construção da memória da ditadura no Brasil », Revista Crítica de Ciências Sociais [Online], 88 | 2010, posto online no dia 01 outubro 2012, consultado o 14 novembro 2019. URL : http://journals.openedition.org/rccs/ 1719 ; DOI : $10.4000 /$ rccs. 1719

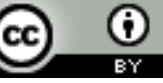




\title{
CECÍLIA MACDOWELL SANTOS
}

\section{Memória na Justiça: \\ A mobilização dos direitos humanos e a construção da memória da ditadura no Brasil}

\begin{abstract}
Este artigo examina o papel da mobilização dos direitos humanos na construção da memória da ditadura no Brasil, baseando-se no caso da Guerrilha do Araguaia, iniciado nos tribunais nacionais em 1982 e encaminhado à Comissão Interamericana de Direitos Humanos em 1995 e à Corte Interamericana de Direitos Humanos em 2009. Travando-se um diálogo crítico com a literatura sobre "justiça de transição", a análise do caso revela que não apenas o Estado como também organizações não-governamentais e ações judiciais de natureza civil desempenham um papel relevante nos processos de constituição de memórias políticas. A atuação do Estado é, por sua vez, mais contraditória do que esta literatura tende a sugerir. A trajetória judicial do caso reflete, por fim, um percurso longo porém dinâmico, no qual o objeto da disputa vai mudando e adquirindo novos significados e os próprios peticionários vão-se alterando, consoante as escalas da disputa e os contextos nacionais e internacionais em que se desenvolvem os conflitos em torno da construção da memória da ditadura.
\end{abstract}

Palavras-chave: Brasil; direitos humanos; ditadura militar; justiça de transição; memória; mobilização jurídica transnacional.

\section{Introdução}

Passados mais de vinte anos desde o fim da ditadura militar no Brasil (1964-1985), o tema do "direito à memória e à verdade" tem vindo a ocupar um lugar de destaque e de divergência na agenda política do governo brasileiro. Desde 2007, a Secretaria Especial de Direitos Humanos (SEDH) e o Ministério da Justiça têm-se manifestado, publicamente, a favor da investigação do passado como uma forma de aprofundamento da democracia, defendendo a não aplicação da Lei de Anistia (Lei 6.683, de 28 de agosto de 1979) aos crimes de tortura, assassinato e desaparecimento forçado praticados pelos agentes do Estado contra os dissidentes políticos durante a ditadura. A Comissão de Anistia do Ministério da Justiça chegou inclusive a editar, a partir de janeiro de 2009, uma revista intitulada "Anistia Política e Justiça de Transição". 
No extremo oposto, o Ministério da Defesa e a Advocacia Geral da União (AGU) consideram que o passado deve ser esquecido em nome da estabilidade política, e defendem que os crimes de tortura estão cobertos pela Lei de Anistia. Esta divergência política ao final do segundo, e último, mandato do Presidente Luiz Inácio Lula da Silva agravou-se quando a SEDH lançou, em dezembro de 2009, o $3^{\circ}$ Programa Nacional de Direitos Humanos, aprovado pelo Presidente Lula (Decreto 7.037, de 21 de dezembro de 2009), elegendo o "direito à memória e à verdade" como um dos seus eixos de orientação, algo inédito nos programas nacionais de direitos humanos no Brasil. ${ }^{1}$ Este novo programa propõe a criação de uma "Comissão Nacional da Verdade" (Secretaria Especial de Direitos Humanos, 2010).

Apesar dos protestos do Ministério da Defesa, a SEDH tem recebido o apoio do Presidente Lula e de setores da sociedade civil para implemen$\operatorname{tar}$ o $3^{\circ}$ PNDH. O Movimento Nacional de Direitos Humanos (MNDH), rede que congrega cerca de 400 organizações de direitos humanos no Brasil, divulgou uma nota pública em dezembro de 2009, repudiando a posição do Ministério da Defesa. De notar que, desde o período da ditadura, grupos de familiares de "mortos e desaparecidos políticos" vêm travando uma luta incessante e muitas vezes solitária pelo "resgate histórico" e pelo fim da impunidade (Teles, 2005).

O que explica a mudança recente da SEDH, do Ministério da Justiça e do MNDH, colocando o "direito à memória e à verdade" no centro de sua agenda política? Qual o papel desempenhado pela mobilização dos direitos humanos no trabalho de construção da memória da ditadura? Como o caso brasileiro contribui para se pensar a relação entre memória e justiça? Como este caso pode contribuir para a literatura - emergente e em expansão nas duas últimas décadas - sobre "justiça de transição"?

Diversos estudos sobre justiça de transição têm destacado o papel constitutivo e seletivo do direito e das instituições judiciais e quasi-judiciais na construção da memória e no estabelecimento de medidas de justiça relativas às atrocidades cometidas no passado (Teitel, 2000; Markovits, 2001; Booth, 2006; Bilsky, 2007). Centrando-se nos contextos de "transição política" e "pós-conflito", com enfoque, em geral, nos tribunais criminais ad hoc ou em comissões extra-judiciais de verdade, justiça e reconciliação, esta literatura tende, porém, a assumir uma certa homogeneidade e linearidade na atuação do Estado, privilegiando as "novas elites políticas" na construção da memória política e da justiça de transição, sem dar a devida

\footnotetext{
${ }^{1}$ Os dois programas anteriores foram lançados em 1996 e 2002, respectivamente, durante o primeiro e o segundo mandatos do então Presidente Fernando Henrique Cardoso.
} 
atenção às iniciativas de diversos setores da sociedade civil no âmbito, por exemplo, da mobilização dos direitos humanos mediante a propositura de ações judiciais de natureza civil.

Embora a mobilização jurídica e transnacional dos direitos humanos não seja o único, ou mesmo decisivo, fator a contribuir para a recente defesa governamental da "justiça de transição" no Brasil, trata-se de um fenômeno importante a ser observado. ${ }^{2}$ Nutrindo-se da crescente "globalização do paradigma de justiça de transição" (Teitel, 2003), a mobilização dos direitos humanos, por parte de setores da sociedade civil e do próprio Estado, parece vir a desempenhar um papel de pressão política relevante para a formulação de novas políticas de "justiça de transição" no Brasil.

A exemplo de outros países da América Latina com um passado recente de regimes autoritários, a mobilização jurídica em escalas nacional e transnacional tem sido um elemento importante para o trabalho de memória e de justiça no Brasil, onde se destaca a mobilização de ex-presos políticos e grupos de familiares de "mortos e desaparecidos políticos" (Teles, 2005). No contexto da ditadura, inúmeras denúncias foram encaminhadas à Comissão Interamericana de Direitos Humanos (CIDH). Durante o período da chamada "abertura política", no início dos anos 1980, algumas ações civis declaratórias contra a União foram promovidas por familiares de "mortos e desaparecidos políticos" (Comissão de Familiares de Mortos e Desaparecidos et al., 2001; Teles, 2005; Moraes, 2006; Santos, 2007). Em 2005 e 2008, ex-presos políticos e seus familiares ajuizaram ações civis declaratórias contra um coronel que comandou um aparelho de tortura em São Paulo. Em 2008, o Ministério Público Federal em São Paulo também promoveu ações civis públicas para apurar a responsabilidade civil dos agentes dos órgãos de repressão. ${ }^{3}$ Estas ações têm em comum, não a pretensão de reparação pecuniária ou de sanção penal, mas o reconhecimento de responsabilidade civil - estatal, nos primeiros casos, pessoal, nos últimos. Os pedidos se referem, entre outras coisas, ao reconhecimento e esclarecimento das circunstâncias das mortes, desaparecimentos ou prisões arbitrárias. A memória política da tortura é um dos principais objetivos dessas ações judiciais.

Para os fins deste artigo, apenas a mobilização jurídica transnacional será objeto de análise. ${ }^{4} \mathrm{O}$ caso da Guerrilha do Araguaia, iniciado nos tribunais

\footnotetext{
${ }^{2}$ A mobilização jurídica transnacional refere-se ao uso do direito para além das fronteiras do Estado-nação. Para uma discussão teórica sobre esta prática à luz do caso brasileiro, ver Santos, 2007. 3 Cf. http://www.prr3.mpf.gov.br/index.php?option=com_content\&task=view\&id=143\&Itemid $=184$, acedido em 15 de janeiro de 2009 .

${ }^{4}$ Este artigo é uma versão modificada de um texto publicado no Brasil (Santos, 2009). Os dados e as idéias aqui contidos baseiam-se na pesquisa por mim coordenada, "Transnational Legal Activism: Brazil and the Inter-American System of Human Rights”, financiada pela University
} 
nacionais em 1982 e encaminhado à CIDH em 1995, merece especial atenção. Embora seja o único caso sobre repressão e memória política encaminhado à CIDH após a ditadura, o exame deste caso contribui para uma reflexão sobre a relação entre memória, justiça e política, ilustrando o papel e os desafios da mobilização dos direitos humanos na construção da memória da ditadura no Brasil. O caso demonstra as contradições da atuação do Estado desde o período da "transição política" até a atualidade. Revela, também, o processo dinâmico através do qual o objeto da disputa judicial foi sendo transformado ou "ressignificado" pelos peticionários ao longo do tempo, e como os próprios peticionários se alteraram. Estas mudanças situam-se, evidentemente, em variados contextos políticos e jurídicos, em escalas nacional e internacional.

A seguir, começo por tecer considerações sobre o conceito e a abordagem da justiça de transição, para a qual o estudo de caso pretende contribuir; segundo, apresento um breve panorama da mobilização da CIDH e dos casos apresentados contra o Brasil durante a ditadura; por fim, examino o caso da Guerrilha do Araguaia, com enfoque nas transformações do objeto da disputa judicial e da sua relação com a construção da memória da ditadura.

\section{O conceito e a genealogia da "justiça de transição"}

Uma breve introdução ao conceito e à abordagem da justiça de transição justifica-se para explicitar o modo como este artigo pretende trazer uma contribuição teórica a esta abordagem: por um lado, o estudo de caso demonstrará a importância e os limites da mobilização jurídica transnacional dos direitos humanos na construção da memória e no trabalho de justiça; por outro lado, o estudo de caso desafiará a visão que predomina nesta abordagem a respeito de uma atuação supostamente linear, progressiva e coerente de diferentes setores do Estado e das políticas de justiça de transição.

O termo transitional justice (justiça de transição) foi cunhado pela professora de direito Ruti Teitel em 1991, referindo-se aos processos de transformação política e jurídica nos contextos de transições para as "novas democracias” na América Latina e na Europa do Leste. Teitel (2000) propõe

\footnotetext{
of San Francisco, à qual agradeço pelo apoio. Agradeço, também, à Fundação para a Ciência e Tecnologia (FCT), que tornou possível a concretização deste trabalho através do contrato de Laboratório Associado com o Centro de Estudos Sociais da Universidade de Coimbra. Sou grata a Mihaela Mihai pela leitura cuidadosa e sugestões para aprimorar esta versão. Agradeço a Teresa Henriques pela estimulante troca de ideias. Agradeço, igualmente, a todas as pessoas que me forneceram informações e dados para esta pesquisa, especialmente Criméia Schmidt de Almeida, pela generosidade com que disponibilizou as cópias digitalizadas de todo o processo judicial da Guerrilha do Araguaia e de documentos afins.
} 
uma abordagem indutiva, construtivista e contextualizada da justiça de transição. De acordo com a autora, o Estado de Direito adquire características excepcionais em momentos fundacionais como os de "transição política" (em oposição a momentos de "normalidade política"): é tanto prospectivo quanto retrospectivo, contínuo e descontínuo, e vai além de suas funções habituais, interligando-se à política em um esforço construtivo. Para a autora, nos momentos de transição, "como a função do direito é promover a construção da mudança política, manifestações jurídicas transicionais são mais vivamente afetadas por valores políticos em regimes de transição do que em contextos onde o Estado de Direito encontra-se firmemente estabelecido" (Teitel, 2000: 215). ${ }^{5}$ Argumenta a autora que, nos momentos de transição política, o direito é tanto constitutivo da política de transição, como constituído por esta política. Em momentos de transição, diferentes ramos do direito contribuem para transformações radicais da comunidade política, e o direito orienta-se para um novo paradigma: a "jurisprudência de transição" (Teitel, 2000: 215).

Em sua genealogia da justiça de transição desde o final da II Guerra Mundial, Teitel (2003) identifica três fases: a primeira, que é marcada pelos Tribunais de Nuremberga, criou importantes precedentes jurídicos, mas foi sui generis, circunscrita aos horrores do Holocausto. A segunda fase refere-se às transições para a democracia na América Latina e à queda do comunismo no bloco soviético a partir dos anos 80 . Esta fase caracterizou-se pela democratização, combinada com algumas medidas de transição e privatização da economia, deixando-se a cargo da iniciativa individual a litigância. A terceira e atual fase caracteriza-se pela normalização e globalização do paradigma de justiça de transição, com um consenso em torno da necessidade de se lidar com o passado. Como acentua Teitel (2000, 2003), os processos políticos e as histórias de cada país variam e moldam as suas medidas de justiça de transição. No entanto, há um crescente consenso em torno de um paradigma dominante de justiça de transição, com um template globalizado de medidas, pelo que alguns autores se referem a uma "agenda global de justiça de transição" ou "agenda pós-conflito" (Lundy e McGovern, 2008: 99). De acordo com Teitel (2003), as principais características deste paradigma são: o legalismo; a divisão de trabalho entre instâncias de justiça locais e internacionais; e um discurso centrado nos direitos humanos. Ao mesmo tempo, no contexto da "guerra contra o terrorismo", verifica-se também um discurso dominante de preservação minimalista do Estado de Direito centrado na manutenção da paz.

5 A autora é responsável por esta e pelas demais traduções adiante citadas. 
Juan Méndez, reconhecido defensor do paradigma da justiça de transição, ex-diretor da Americas Watch e ex-presidente da Comissão Interamericana de Direitos Humanos, aponta quatro principais áreas de atuação da justiça de transição, que, a seu ver, devem ser da responsabilidade do Estado. Primeiro, a "justiça" num sentido restrito, referindo-se sobretudo a processos criminais com vistas à apuração da responsabilidade penal dos responsáveis por graves violações de direitos humanos. Em segundo lugar, o "direito à verdade e à informação", que pode ser exercido por meio do estabelecimento de comissões de verdade, justiça e/ou reconciliação. Estas em geral contribuem para o trabalho de "memória política" e de "reconstituição da história oficial". Terceiro, a "reparação", alcançada por via administrativa mediante o pagamento de indenizações, ou por meio de medidas políticas simbólicas, como, por exemplo, o pedido de perdão. Quarto, a "administração”, no âmbito da qual deve-se impedir que funcionários ou representantes do Estado que cometeram graves violações de direitos humanos continuem a exercer funções públicas (Méndez, 2001). ${ }^{6}$

Em dois aspectos considero a abordagem da justiça de transição importante para a compreensão das mobilizações jurídicas que envolvem a memória política. Primeiro, o contexto político é um elemento fundamental que molda e é moldado pelas medidas de justiça, donde a relação de interdependência entre o direito e a política. Segundo, o direito contribui para a construção da memória política e da história, e o faz de maneira seletiva (Markovits, 2001; Douglas, 2001; Jelin, 2003; Booth, 2006). O trabalho da justiça, como afirma W. James Booth (2006), é simultaneamente um trabalho da memória, donde o autor referir-se ao binômio "justiça-memória". A exemplo da narrativa histórica e memorialística, a narrativa jurídica é retrospectiva, seletiva e envolve relações de poder e contestação (Booth, 2006). Dado que o discurso jurídico estabelece responsabilidades e sanções, o direito distingue-se, segundo Booth, por constituir um "regime de temporalidade": "decide sobre os crimes que permanecerão para sempre acionáveis (imprescritíveis), as injustiças que ficarão completamente fora do alcance da esfera de ação jurídica, bem como os crimes (através da ação na esfera política) que ficarão sujeitos à anistia ou ao esquecimento judicial" (Booth, 2006: 116). Nesse sentido, torna-se fundamental examinar as

\footnotetext{
${ }^{6}$ Os defensores da justiça de transição têm refletido sobre as contribuições e os limites das medidas de justiça para a promoção de processos de democratização e de paz (Oziel, 1997; Teitel, 2000; McAdams, 2001; Minow, 2002; Rosenblum, 2002; Misztal, 2005; Mihai, 2009). Alguns estudos de caso abordam a efetividade de diferentes aspectos de medidas de justiça de transição e como o template globalizado deste modelo de justiça deve adaptar-se a cada contexto nacional e local (Urs, 2007; Rose e Ssekandi, 2007; Duthie, 2008; McEvoy e McGregor, 2008).
} 
relações de poder que tecem as práticas dos tribunais e a ação política nos processos de constituição da memória política.

No entanto, a abordagem dominante da justiça de transição apresenta algumas limitações teóricas e analíticas. Uma das questões a ser problematizada refere-se à maneira como se pensa a relação entre o direito e a política. Ao contrário do argumento de Teitel, no sentido de que o direito está mais influenciado pelo contexto político nos momentos de transição, os estudos críticos do direito mostram que o direito e a política estão intimamente ligados em qualquer contexto político. ${ }^{7}$ Os processos criminais que tramitaram na justiça militar brasileira, entre março de 1964 e abril de 1979, estavam tão influenciados pelo contexto político repressivo daquele momento quanto a Lei de Anistia de 1979 foi moldada pelo contexto político da chamada "abertura lenta, gradual e segura" ${ }^{8}$ No mesmo sentido, as recentes ações civis declaratórias contra torturadores também são influenciadas pelo contexto político que atualmente se considera "democrático" e que é marcado pela globalização dos direitos humanos e do paradigma de justiça de transição. Conforme será examinado adiante, sucessivos e variados contextos políticos influenciaram o percurso e as transformações do caso da Guerrilha do Araguaia, desde a sua entrada nos tribunais nacionais em 1982, a posterior entrada na Comissão Interamericana de Direitos Humanos em 1995 e a entrada mais recente na Corte Interamericana de Direitos Humanos em 2009.

O legalismo e a centralidade do Estado na "agenda global da justiça de transição" são outros aspectos desta literatura que podem ser questionados (McEvoy, 2008; McEvoy e McGregor, 2008). Como salientam McEvoy e McGregor (2008), o Estado e os tribunais nacionais e internacionais não são os únicos atores que fazem os trabalhos da justiça, da memória e da recuperação da história. Em diversos casos, organizações de vítimas e familiares, ONGs e grupos comunitários participam nos processos de justiça de transição.

\footnotetext{
${ }^{7}$ No Brasil, podem-se referir os estudos sociológicos e críticos do direito realizados a partir dos anos 80 por Joaquim Falcão, José Eduardo Faria, Luciano Oliveira, Alexandrina Sobreira de Moura, Eliane Junqueira, entre outros. Para uma ilustração de como o direito e a política estão intimamente relacionados, ver, por exemplo, a resenha de Junqueira (1996) a respeito da produção sociojurídica sobre o acesso à justiça.

${ }^{8}$ Ver Arquidiocese de São Paulo para uma leitura crítica desses processos criminais, utilizados, no seu Projeto "Brasil: nunca mais", para se fazer "uma radiografia inédita da repressão política" e uma "anatomia da resistência" (2003: 24). Para uma análise política crítica e contextualizada das lutas em torno da votação e da aplicação da Lei de Anista (Lei 6.683, de 28 de agosto de 1979) no Brasil, e dos significados que esta lei adquiriu desde 1979 até 2007, ver Mezarobba (2009) e Soares e Prado (2009).
} 
O "regime de temporalidade" estabelecido pelo direito estatal pode, por sua vez, sofrer mudanças ao longo do tempo, já que as forças jurídicas podem divergir entre si e também se encontram em constante tensão com múltiplas forças sociais e políticas (Di Paolantonio, 2004). A abordagem da justiça de transição tende, porém, a assumir uma progressividade e coerência na atuação do Estado (Santos, 2009).

As concepções de transição e de democratização presentes na abordagem dominante da justiça de transição também merecem ser questionadas. Obviamente, é muito difícil determinar com precisão o início e o fim de um período de transição. Mas este não é o principal problema. Mesmo que a literatura sobre justiça de transição trate, como vem fazendo, a "transição" a partir de um marco temporal mais alargado e maleável, esta literatura tende a conceber os processos de democratização de maneira linear, como uma nova fase política que corresponde mais a uma ruptura do que a continuidades históricas, como se a nova ordem política e jurídica fosse constituída apenas por novos atores, por uma nova elite, desvinculada do passado, livre de relações de poder (McEvoy e McGregor, 2008). ${ }^{9}$

De fato, os processos de mudança política são mais descontínuos do que a literatura sobre justiça de transição parece indicar. O Estado é pouco problematizado nesta literatura, como se a atuação e a cultura dos seus diversos setores fossem orientadas para um mesmo fim - o da "justiça de transição" - nos chamados períodos de "transição política". Como adiante será referido, o caso da Guerrilha do Araguaia revela claramente as contradições e as lutas internas do Estado na sua atuação ambígua em prol da construção de uma "justiça de transição" no Brasil.

Por fim, a mobilização jurídica em torno da responsabilidade do Estado pelas violações aos direitos políticos e pelo resgate da memória política não se restringe aos períodos de transição, como demonstram os casos contra o Brasil apresentados à CIDH durante a ditadura.

\section{A CIDH e a mobilização transnacional dos direitos humanos durante a ditadura}

A principal função da Comissão Interamericana de Direitos Humanos (CIDH), criada em 1959, é garantir a defesa dos direitos humanos no continente americano, averiguando as alegadas violações e recomendando

\footnotetext{
${ }^{9}$ Como assinala Vasconcelos (2009), a literatura sobre justiça de transição em geral absorve acriticamente as concepções liberais, elitistas e lineares de "transição" e "democratização", formuladas por cientistas políticos como Juan Linz, entre outros. Consequentemente, as mesmas críticas feitas por autores que defendem um modelo de "democracia participativa", a exemplo de Boaventura de Sousa Santos e Leonardo Avritzer, podem ser aplicadas à abordagem dominante da justiça de transição.
} 
os mecanismos cabíveis de proteção e reparação aos Estados-membros da Organização dos Estados Americanos (OEA). Os instrumentos normativos da CIDH são a Carta da Organização dos Estados Americanos, a Declaração Americana dos Direitos e Deveres do Homem, ambas adotadas pela OEA em 1948, e a Convenção Americana de Direitos Humanos, adotada pela OEA em 1969 e em vigor desde 1978. A Convenção estabeleceu que dois órgãos deveriam integrar o sistema de proteção dos direitos humanos na região: a CIDH e a Corte Interamericana de Direitos Humanos. A CIDH possui atribuições para receber petições e denúncias independente de os Estados haverem ratificado a Convenção ou reconhecerem a jurisdição da Corte. Mas a CIDH é um órgão quasi-judicial e, ao contrário da Corte, as suas decisões (resoluções e recomendações) não gozam de caráter jurídico vinculante.

Qualquer indivíduo, grupo de pessoas ou organização da sociedade civil tem legitimidade processual ativa perante a $\mathrm{CIDH}$, independentemente de haver sofrido uma violação. Uma vez que esta legitimidade processual não se estende à Corte, a mobilização jurídica transnacional tem sido dirigida diretamente à CIDH. ${ }^{10} \mathrm{Na}$ última década, tal mobilização tem-se intensificado. Os relatórios anuais da CIDH revelam um aumento significativo do número de denúncias ao longo dos anos - ainda que estes relatórios, publicados desde 1970, não apresentem dados organizados de maneira uniforme e sistemática, sobretudo entre 1970 e $1985 .{ }^{11}$ O elevado aumento do número de denúncias - que tem sobrecarregado e tornado muito lento o trabalho da CIDH - pode ser atribuído a transformações políticas em escalas nacional e regional. Até aos anos 80, os governos militares e outros regimes autoritários mantinham, nos órgãos da OEA, representantes que davam pouco valor ao seu sistema de proteção dos direitos humanos. $\mathrm{O}$ processo de democratização na região ajudou a fortalecer a OEA e este sistema, que adquiriu maior legitimidade perante as organizações não-governamentais (ONGs) de direitos humanos (Hanashiro, 2001).

O Brasil ratificou a Convenção em 1992 e reconheceu a jurisdição da Corte em 1998 - com muito atraso em comparação com os demais países da América Latina (Santos, 2007). Durante a ditadura, o número de denúncias apresentadas contra o Brasil na $\mathrm{CIDH}$ foi maior do que nos anos 80,

\footnotetext{
${ }^{10}$ Apenas os Estados-partes da Convenção e a CIDH podem encaminhar casos à Corte Interamericana de Direitos Humanos.

${ }^{11}$ Em 1969 e 1970, por exemplo, a CIDH recebeu 217 petições, metade do número recebido apenas em 1997 (435). Esse número triplicou em 2006 (1325). Para mais detalhes, ver os relatórios anuais da CIDH de 1969-1970, 1997 e 2006, publicados em http://www.cidh.org/Default.htm. Ver Piovesan (2006) e Santos (2007) para um perfil dos tipos de casos contra o Brasil encaminhados à CIDH após a ditadura militar.
} 
no período de redemocratização. Desde o ano 2000, este número voltou a crescer. Em 1969 e 1970, por exemplo, a CIDH recebeu 40 denúncias contra o Brasil, e o país ocupou o segundo lugar em número de petições no continente americano. Em 1999 e 2000, o número de denúncias contra o Brasil diminuiu (35). Em 2006, esse número quase dobrou (66), tendo o país assumido a sétima posição na região. ${ }^{12}$

Os autores das denúncias contra o Brasil só passaram a ser citados nos relatórios anuais da $\mathrm{CIDH}$ a partir dos anos 80. Desde então, verifica-se que a maior parte dos casos foi encaminhada por ONGs internacionais de direitos humanos, em parceria com ONGs locais, entidades de diferentes segmentos dos movimentos sociais, além das vítimas ou seus familiares. Os peticionários recorrem à CIDH não somente para obter reparações individuais, mas também para obter decisões e criar precedentes que poderão ter algum impacto em políticas públicas, na legislação e na sociedade brasileiras (Cavallaro, 2002; Affonso e Freund, 2005; Santos, 2007; Cavallaro e Brewer, 2008).

Durante a ditadura, a CIDH ignorou a maioria das denúncias apresentadas contra o Brasil. Entre 1969 e 1973, por exemplo, a CIDH recebeu, pelo menos, 77 petições contra o Brasil. De entre essas, 20 foram aceitas como "casos concretos". Com exceção de um, os casos diziam respeito a práticas de tortura, prisão arbitrária, ameaça de morte, desaparecimento forçado e assassinato, perpetrados por agentes do Estado contra dissidentes políticos do regime. Quando respondia aos comunicados da CIDH, o Estado brasileiro negava sistematicamente a ocorrência das alegadas violações. E a CIDH concluía que a maior parte dos casos era inadmissível ou que deveria ser arquivada. ${ }^{13}$

Até meados dos anos 80, o primeiro caso em que a CIDH decidiu que o Estado brasileiro fora responsável por violações aos direitos humanos foi o caso do líder sindical Olavo Hansen, preso arbitrariamente, torturado e assassinado nas dependências do Departamento Estadual de Ordem Política e Social (DOPS), em São Paulo, em maio de $1970 .{ }^{14} \mathrm{O}$ caso Hansen tramitou na CIDH entre meados de 1970 e finais de 1973, tendo o seu histórico

\footnotetext{
${ }^{12}$ Mais detalhes podem ser encontrados nos relatórios anuais da CIDH, publicados em http://www. cidh.org/Default.htm.

${ }^{13}$ Cf. os relatórios anuais da CIDH de 1969-1970, 1999, 2000 e 2006, publicados em http://www. cidh.org/Default.htm. De notar que, devido à precária sistematização dos dados apresentados nesses relatórios, há divergências, embora mínimas, entre os números citados em diferentes estudos que abordam os casos contra o Brasil no Sistema Interamericano de Direitos Humanos. Ver, por exemplo, Teles (2005), Piovesan (2006) e Santos (2007).

${ }^{14}$ Para mais detalhes sobre as circunstâncias da morte de Hansen e das denúncias feitas no Brasil, ver Pereira Neto (2009).
} 
e a decisão da $\mathrm{CIDH}$ a respeito do mesmo sido publicados no relatório anual de 1973 da CIDH. ${ }^{15}$

Em junho de 1970, a CIDH recebeu uma comunicação de várias pessoas denunciando o Estado brasileiro pelo "assassinato do dirigente sindical Olavo Hansen" ${ }^{16}$ Os relatórios anuais da CIDH que citam o caso não indicam os nomes dos autores desta denúncia. Mas informam que, dias depois e em outubro do mesmo ano, a denúncia foi corroborada em diferentes comunicações remetidas à $\mathrm{CIDH}$ por várias pessoas e entidades. ${ }^{17}$ Eis uma situação clara de mobilização jurídica transnacional dos direitos humanos, a refletir o padrão boomerang referido por Keck e Sikkink (1998), ilustrando também o que Santos e Rodríguez-Garavito (2005) designam por "cosmopolitanismo jurídico subalterno" e o que Santos (2007) denomina de "ativismo jurídico transnacional".

Contra a tese de suicídio, mantida pelo governo brasileiro até o fim da tramitação do caso na $\mathrm{CIDH}$, os autores da denúncia defendiam que a prisão, violência física e morte de Hansen deveriam ser consideradas como um "crime político e sindical". No cerne deste caso estava, portanto, não apenas a responsabilização do Estado brasileiro pela grave violação aos direitos humanos, como também o esclarecimento das circunstâncias da morte de Olavo Hansen - um trabalho de justiça-memória que prescindia do acesso a informações. Mas, naquela época, como hoje, a dificuldade de acesso a determinadas informações era um dos maiores empecilhos para o trabalho de justiça-memória.

A CIDH reconheceu a prática de tortura e concluiu que se tratava de um "caso gravíssimo de violação do direito à vida". Recomendou ao governo brasileiro: "que se imponham aos que forem julgados culpados desta morte as sanções previstas por lei para tal caso e se ofereça aos parentes de Olavo Hansen a reparação que por direito lhes corresponda" ${ }^{18} \mathrm{O}$ governo em

\footnotetext{
${ }_{15}$ Caso 1683, Informe Anual de la Comisión Interamericana de Derechos Humanos 1973, OEA/Ser. L/V/II.32 doc. 3 rev. 2, 14 de fevereiro de 1974, disponível em http://www.cidh.org/annualrep/ $73 \mathrm{sp} /$ indice.htm. Os dados que se seguem sobre o caso Hansen serão extraídos deste relatório. O Caso 1684, denunciado à CIDH na sequência do caso Hansen (Caso 1683), destaca-se também pelo reconhecimento, por parte da CIDH, de "forte presunção de que no Brasil há sérios casos de tortura" (apud Piovesan, 2006: 284-286).

${ }_{16}$ Antes de ter sido encaminhado à CIDH, o caso Hansen foi denunciado junto ao Congresso Nacional por " 27 sindicatos de São Paulo e 5 Federações, pela Igreja, intelectuais, estudantes e organizações sindicais latino-americanas" (Teles, 2005: 70). O Conselho de Defesa dos Direitos da Pessoa Humana (CDDPH), presidido pelo então Ministro da Justiça Alfredo Buzaid, confirmou a tese de suicídio adotada pela Justiça Militar, onde tramitara o processo criminal (cf. supra).

17 Ver os relatórios anuais de 1970, 1971 e 1973 da CIDH, disponíveis em http://www.cidh. org/Default.htm.

${ }^{18}$ Cf. supra.
} 
vão solicitou a reconsideração desta decisão e chegou inclusive a enviar à $\mathrm{CIDH}$ uma nota de repúdio por intermédio do seu embaixador representante perante a OEA. Nesta nota desafiava a legitimidade da CIDH e invocava a decisão contrária da Organização Internacional do Trabalho (OIT) sobre o mesmo caso. A CIDH manteve a sua decisão e publicou-a no seu relatório anual de 1973, encaminhado à Assembleia Geral da OEA. O Brasil foi, assim, exposto, internacionalmente, pela prática de tortura e de outros gravíssimos crimes contra a vida.

Mas a decisão excepcional da CIDH não teve qualquer repercussão no cenário político-jurídico brasileiro, sendo pouco citada na literatura sobre o uso do Sistema Interamericano de Direitos Humanos no Brasil. ${ }^{19} \mathrm{Na}$ época, o contexto nacional e internacional era marcado pela quase absoluta conivência das instituições jurídicas face às atrocidades cometidas pelos governos militares e autoritários.

\section{A mobilização dos direitos humanos a partir da "transição" e a memó- ria da ditadura: o caso da Guerrilha do Araguaia}

A partir dos anos 80, o caso da Guerrilha do Araguaia, iniciado em 1982 nos tribunais nacionais e ainda em tramitação no Sistema Interamericano de Direitos Humanos, foi o único apresentado contra o Brasil perante a $\mathrm{CIDH}$ a incidir sobre os crimes praticados pelos órgãos de repressão contra dissidentes políticos do regime militar. Além de sua relevância histórica, trata-se de um caso paradigmático da mobilização jurídica nacional e transnacional em prol da reconstrução da memória da ditadura. Este caso é importante por três razões principais. Primeiro, mostra claramente como o direito e a política se influenciam reciprocamente ao longo de diferentes contextos políticos. Segundo, ilustra a incansável mobilização dos direitos humanos por parte de atores organizados da sociedade civil, que usam a disputa judicial, tanto em escala nacional como transnacional, como parte de uma estratégia de luta social e política em prol do "direito à memória e à verdade”. Terceiro, mostra como o Estado atua de maneira contraditória ao longo de diferentes momentos políticos. Estes aspectos da mobilização dos direitos humanos e da atuação do Estado podem ser observados em três momentos que delimitaram o percurso e o objeto da disputa judicial: a partir do seu início em 1982; a partir de 1995, quando o caso foi levado à CIDH; e desde 2009, quando encaminhado à Corte Interamericana de Direitos Humanos.

${ }_{19}$ Para exceções, ver Teles $(2005)$, que destaca a relevância histórica deste caso em sua tese de mestrado. Ver também Santos $(2007 ; 2009)$. 
O movimento da Guerrilha do Araguaia começou a se desenvolver em 1966, numa área rural de difícil acesso, no sul do Pará. Sob a direção do Partido Comunista do Brasil (PCdoB), 69 militantes de diferentes partes do Brasil integraram a guerrilha, que agregou, também, cerca de 17 camponeses da localidade. Entre abril de 1972 e janeiro de 1975, o Exército brasileiro realizou campanhas de "informação e repressão" da guerrilha, dizimando-a no final de 1974. Estima-se que o número de soldados que participaram das campanhas oscilou entre 3 mil e mais de 10000 (Comissão Especial sobre Mortos e Desaparecidos Políticos, 2007: 195). Independentemente das divergências sobre este dado, é reconhecida a desproporção entre o número de soldados, por um lado, e o de militantes, por outro.

Os relatos dos militantes sobreviventes e dos moradores locais confirmam que a repressão era generalizada. A prática da tortura era sistemática. As Forças Armadas tencionavam não deixar qualquer vestígio da operação militar e pretendiam apagar a guerrilha da história do Brasil. $\mathrm{Na}$ segunda metade dos anos 70, o governo militar impôs silêncio absoluto sobre o assunto, proibiu a imprensa de dar notícias, e o Exército negou a existência do movimento (Comissão Especial sobre Mortos e Desaparecidos Políticos, 2007; Teles, 2005). Ao contrário da versão do Exército de haver incinerado todos os corpos dos militantes, algumas ossadas foram descobertas desde os anos 90, tendo apenas uma sido identificada como os restos mortais de uma militante (Comissão Especial sobre Mortos e Desaparecidos Políticos, 2007).

\subsection{O início da disputa judicial em 1982: o pedido no contexto da Lei de Anistia}

A Lei de Anistia de 1979 foi, e continua sendo, criticada por diversos grupos sociais e políticos no Brasil em função de ter estendido a anistia aos agentes do Estado que praticaram os crimes de tortura, desaparecimento forçado e execução extra-judicial durante a ditadura. A lei "forjada pelo arbítrio" foi fruto de uma "transição pelo alto", controlada pelos militares e seus aliados civis, tendo como objetivo impor o silêncio sobre o passado e a impunidade (Mezarobba, 2009; Soares e Prado, 2009; Teles, 2005). Foi neste contexto de limitada "abertura política" que os familiares dos "desaparecidos" na Guerrilha do Araguaia recorreram ao Judiciário, com o intuito de localizar os corpos dos seus familiares e resgatar a história deste movimento e da repressão (Teles, 2005).

A disputa judicial no âmbito do direito interno começou em março de 1982, quando 22 familiares de militantes do PCdoB "desaparecidos" na Guerrilha do Araguaia ajuizaram uma "ação ordinária para prestação 
de fato" contra a União Federal, perante a Justiça Federal, no Distrito Federal..$^{20} \mathrm{~A}$ tramitação deste processo judicial durou mais de vinte anos, com a decisão sobre o mérito tendo vindo a transitar em julgado apenas em meados de 2007. A sentença ainda aguarda execução judicial. A morosidade da justiça, que como se verá adiante também ocorre no âmbito da justiça internacional, mostra que a concepção de "justiça de transição" assume, equivocadamente, uma visão linear e conclusiva do trabalho de justiça-memória. Mas se, por um lado, a morosidade da justiça significa falta de justiça, a disputa judicial ininterrupta cria, por outro lado, uma oportunidade para se utilizar o caso da Guerrilha do Araguaia como um instrumento adicional de pressão política ao longo de diferentes momentos em que a luta social, política e jurídica em torno do "direito à memória e à verdade" vai-se redefinindo.

No início do caso, um dos principais objetos da disputa referia-se ao próprio "acontecimento" histórico da guerrilha. Na petição inicial (folhas 1-22), os autores enfatizaram a existência da Guerrilha do Araguaia e o desaparecimento forçado dos militantes como "fatos incontestáveis". Com base nas Convenções de Genebra formularam três pedidos de obrigação de fazer por parte da União: que esta fosse compelida a localizar os corpos dos seus parentes e trasladasse os mesmos; que esclarecesse as "circunstâncias em que as mortes se operaram, para que não seja fragmentada a história de suas vidas"; e que proporcionasse o acesso a informações em poder das Forças Armadas, para possibilitar a execução dos demais pedidos, mediante a apresentação do "relatório oficial do Ministério da Guerra datado de 20 de janeiro de 1975". Embora o reconhecimento dos crimes de tortura e de desaparecimento forçado fosse um dos objetivos desta ação declaratória, a formulação do pedido e o seu alcance eram delimitados pelo contexto político daquele momento de "transição pelo alto". Não se podia discutir a responsabilidade dos agentes do Estado pelos crimes da ditadura, ao contrário do que ocorreu a partir de 2009, quando o caso foi encaminhado à Corte Interamericana de Direitos Humanos, como se verá adiante.

$\mathrm{Na}$ contestação (folhas 169-211), a União não reconheceu a Guerrilha do Araguaia como uma verdadeira guerrilha, senão como a "constituição de pequenos "bandos" de esquerdistas". Negou a existência do relatório oficial citado pelos autores, acrescentando que, ainda que existente, não poderia ser divulgado em virtude de seu caráter secreto. Apontou diversos vícios da ação e pediu, por fim, a improcedência com base na impossibilidade jurídica do

${ }^{20}$ Processo $^{\circ}$ I-44/82-B, renumerado como Processo ${ }^{\circ}$ I-108/83, $1^{\text {a }}$ Vara da Justiça Federal do Distrito Federal. 
pedido, ilegitimidade processual passiva, ausência de interesse processual, impropriedade da via processual eleita e prescrição da ação.

No despacho saneador (folhas 216-218), proferido em 24 de setembro de 1982, o juiz que na época presidia o processo, Manoel Lauro Volkmer de Castilho, confirmou a existência da Guerrilha do Araguaia, com base na ampla documentação fornecida pelos autores (folhas 23-159), e rejeitou todos os vícios alegados pela União, exceto a impossibilidade jurídica do pedido, sobre o qual não teceu considerações.

Em 27 de março de 1989, passados sete anos desde o início da ação, o juiz federal que então presidia o processo, Vicente Leal de Araújo, proferiu a primeira sentença sobre o caso, julgando "extinto o processo, sem conhecimento do mérito, por considerar os autores carecedores de ação" (folhas 634-641). De notar que no ano de 1989 ocorreu a primeira eleição presidencial após o fim da ditadura. Fernando Collor de Melo venceu a eleição com uma pequena margem de votos à frente de Luiz Inácio Lula da Silva. Collor foi impeached no meio do seu mandato, em função de prática de corrupção.

Nesse contexto frágil da construção da democracia, o juiz Araújo não negou a existência da Guerrilha do Araguaia e do conflito armado entre os militantes dos PCdoB e as tropas das Forças Armadas. Mas afastou a aplicação das Convenções de Genebra por entender que este conflito "não se encasa no conceito de guerra". Julgou também ser imprópria a via judicial escolhida, alegando que a Lei de Anistia permitia a solicitação de uma "declaração de ausência". Do ponto de vista fático, julgou impossível localizar os corpos sepultados e impor à União Federal a obrigação de encontrá-los "em regiões inóspitas", "no meio da selva".

Os autores apresentaram um recurso de apelação. O Tribunal Regional Federal deu provimento à apelação, por unanimidade, determinando o julgamento do mérito da demanda. Mas a União apresentou, sem sucesso, um recurso, e continuou a usar todos os instrumentos jurídicos possíveis para protelar o julgamento do mérito. Interpôs diversos tipos de recursos até à data da decisão favorável de 2003, adiante comentada, e até o seu trânsito em julgado, em maio de 2007, sem até hoje ter dado cumprimento a tal decisão.

\subsection{Novos atores transnacionalizam o caso no contexto da globalização dos direitos humanos}

No transcorrer desta longa e ainda inacabada disputa judicial, grupos de familiares de mortos e desaparecidos políticos continuaram a se mobilizar e a organizar redes de denúncia e solidariedade, acionando diversas instituições e entidades de direitos humanos, internacionais e nacionais (Teles, 2005). 
No início dos anos 90, membros da Comissão de Familiares de Mortos e Desaparecidos Políticos (CFMDP), sediada em São Paulo, os quais vinham acompanhando de perto e envidando esforços para levar adiante o caso da Guerrilha do Araguaia, reuniram-se com advogados que representavam ONGs internacionais de direitos humanos no Brasil para estudar a possibilidade de encaminharem o caso da Guerrilha do Araguaia à CIDH.

Com efeito, em 7 de agosto de 1995, treze anos e quatro meses após a propositura da ação judicial contra a União na Justiça Federal em Brasília, a CIDH recebeu uma petição contra o Estado do Brasil, apresentada pela seção brasileira do Centro pela Justiça e Direito Internacional (CEJIL-Brasil) e pela Human Rights Watch/Americas, referindo-se ao desaparecimento forçado dos membros da Guerrilha do Araguaia e à falta de providências pelo Estado, incluindo a morosidade do Judiciário brasileiro no processamento da ação judicial iniciada em 1982. Posteriormente, a Comissão de Familiares de Mortos e Desaparecidos Políticos (CFMDP) e o Grupo Tortura Nunca Mais do Rio de Janeiro (GTNM-RJ) foram acrescentados como co-peticionários. ${ }^{21} \mathrm{~A}$ transnacionalização do caso denota a falta de justiça no âmbito do direito interno e a falta de respostas políticas satisfatórias por parte do Estado. Esta mobilização transnacional dos direitos humanos ampliou a rede dos sujeitos envolvidos diretamente na disputa, agora de natureza quasi-judicial, trazendo novos aliados internacionais. Tornou mais visível, na tramitação do caso, os dois principais protagonistas das mobilizações nacionais pelo "direito à memória e à verdade", como a CFMDP e o GTNM-RJ, entidades da sociedade civil compostas por familiares de desaparecidos políticos e ex-presos políticos, as quais não apareciam diretamente no processo judicial no âmbito interno.

Em dezembro de 1995, a CIDH encaminhou ao governo brasileiro a petição recebida e os demais documentos que acompanharam a denúncia. O Estado respondeu em meados de 1996. Não contestou os fatos alegados pelos peticionários quanto à existência da Guerrilha do Araguaia e ao conflito armado entre militantes e as tropas das Forças Armadas. Todavia, argumentou que os recursos internos não haviam sido esgotados pelos peticionários. Além disso, alegou que a denúncia perdera o seu objeto, uma vez que, com a adoção da Lei 9.140/1995, que criara a Comissão Especial sobre Mortos e Desaparecidos Políticos, o Estado reconhecera "a responsabilidade civil e administrativa de seus agentes pelos fatos denunciados" e proveria a devida indenização aos familiares dos mortos ou desaparecidos políticos.

${ }^{21}$ Caso 11.552, Relatório 33/01, Comissão Interamericana de Direitos Humanos, disponível em http://www.cidh.org/annualrep/2000port/11552.htm. 
Em resposta, os peticionários argumentaram que tal reparação não era suficiente para conhecerem as circunstâncias das mortes e desaparecimentos forçados, objeto da ação civil de prestação de fato pendente na Justiça Federal. $\mathrm{Na}$ verdade, uma das motivações da CFMDP para encaminhar o caso da Guerrilha do Araguaia à CIDH decorreu dos limites das negociações políticas que a CFMDP vinha travando com o governo de Fernando Henrique Cardoso para que se estabelecesse uma comissão de reparação e de justiça. O caso foi apresentado à CIDH pouco antes de a Lei 9.140/1995 ter sido sancionada. Apesar dos avanços desta lei, a CFMDP e o GTNM-RJ apontavam alguns limites na nova legislação e nos poderes da Comissão Especial sobre Mortos e Desaparecidos: o ônus da prova era dos familiares; as circunstâncias das mortes e desaparecimentos não podiam ser esclarecidas; os agentes do Estado responsáveis pelos crimes de tortura, assassinato e desaparecimento forçado continuavam protegidos pela Lei de Anistia (Teles, 2001).

No seu relatório sobre a admissibilidade do caso, publicado em 2001, a CIDH considerou que, "no estado atual do procedimento, não se pode afirmar com certeza que as medidas adotadas pelo Estado constituem ou não uma 'reparação suficiente' das violações alegadas”. Dispensou o requisito do esgotamento dos recursos internos, considerando que "a demora de mais de 18 anos sem uma decisão definitiva de mérito não pode ser considerada razoável". ${ }^{22}$ Assim, a CIDH publicou o relatório de admissibilidade, deixando para decidir sobre o mérito após a coleta de mais dados. Ironicamente, a morosidade do judiciário brasileiro repetiu-se no âmbito da justiça internacional: até dezembro de 2008, o caso ainda se encontrava em andamento na $\mathrm{CIDH}$, ou seja, pelo mesmo decurso de treze anos e quatro meses que levou os familiares e seus aliados internacionais a acionarem a CIDH em 1995. Em que pese esta morosidade, o relatório de admissibilidade de 2001 foi uma primeira vitória da mobilização jurídica transnacional em torno do caso da Guerrilha do Araguaia.

Mas a mobilização da CIDH não teve o impacto político almejado pelos peticionários. As medidas de "justiça de transição" promovidas pelo governo de Fernando Henrique Cardoso ao longo de dois mandatos, entre 1994 e 2002, não foram além de indenizações aos familiares dos mortos e desaparecidos políticos. O governo de Cardoso opunha-se à criação de uma comissão de verdade, por exemplo, e não envidou esforços para possibilitar o acesso às possíveis informações em poder dos militares sobre a Guerrilha do Araguaia. Nas vésperas do final do governo, o Presidente Cardoso assinou o Decreto 4.553, de 27 de dezembro de 2002, que veio alargar os

${ }^{22}$ Cf. supra. 
prazos para o acesso a informações ou documentos classificados como sigilosos, determinando que "o prazo de duração da classificação ultra-secreto poderá ser renovado indefinidamente, de acordo com o interesse da segurança da sociedade e do Estado" (art. $7^{\circ}$, par. $1^{\circ}$ ).

A posse do Presidente Lula em janeiro de 2003 trouxe grande esperança para o movimento de direitos humanos. Mas em matéria do direito à memória e ao acesso a informações, o novo governo consolidou a orientação do governo anterior através do estabelecimento da Medida Provisória 228, de 9 de dezembro de 2004, e do Decreto 5.301, também de 9 de dezembro de 2004. O governo de Lula inclusive propôs ao Congresso um projeto de lei que se transformou na Lei 11.111, de 5 de maio de 2005, ainda em vigor, a qual manteve a figura do "sigilo eterno" tão criticado por grupos de familiares de mortos, desaparecidos políticos e ex-presos políticos.

Apesar do contexto político nacional desfavorável, havia um novo contexto jurídico internacional que favorecia as mobilizações em torno do “direito à memória e à verdade". Em março de 2001, a Corte Interamericana de Direitos Humanos proferiu uma sentença histórica no caso Barrios Altos c. Peru, sustentando que as leis de "auto-anistia", como as leis peruanas 26479 e 26 492, que excluem a responsabilidade por graves violações dos direitos humanos, como a tortura e o desaparecimento forçado, são inadmissíveis, não são verdadeiras leis. Como destaca Cançado Trindade, que então presidia a Corte, "foi a primeira vez, no Direito Internacional contemporâneo, que um tribunal internacional fulminou uma lei de auto-anistia". Explica o jurista e ex-presidente da Corte que, "ao impedir o acesso das vítimas e seus familiares à verdade e à Justiça, são (as leis de auto-anistia) violadoras dos artigos 1(1), 2, 8 e 25 da Convenção (par. 41 e 43)". ${ }^{23}$

Neste novo cenário da jurisprudência internacional dos direitos humanos, a juíza federal Solange Salgado, então titular da $1^{a}$ Vara da Justiça Federal onde tramitava a ação judicial do caso da Guerrilha do Araguaia, iniciada em 1982, proferiu, em 20 de junho de 2003, uma decisão histórica, julgando o mérito da demanda em favor dos autores (folhas 1318-1360). Fundamentando a decisão em normas constitucionais e na jurisprudência da Corte Interamericana de Direitos Humanos, a juíza declarou, entre outras coisas:

A entrega dos restos mortais das vítimas aos familiares, a fim de que possam ser dignamente sepultados, e o fornecimento das informações sobre a morte, deve constar do rol das medidas internas de otimização dos direitos humanos, capazes de dar cumprimento à obrigação estatal.

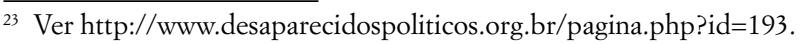




\section{E determinou:}

1 - a quebra de sigilo das informações militares relativas a todas as operações realizadas no combate à Guerrilha do Araguaia;

2 - à Ré que, no prazo de 120 (cento e vinte) dias, informe a este Juízo onde estão sepultados os restos mortais dos familiares dos Autores, mortos na Guerrilha do Araguaia, bem como para que proceda ao traslado das ossadas, o sepultamento destas em local a ser indicado pelos Autores, fornecendo-lhes, ainda, as informações necessárias à lavratura das certidões de óbito;

3 - à Ré que, no prazo de 120 (cento e vinte) dias, apresente a este Juízo todas as informações relativas à totalidade das operações militares relacionadas à Guerrilha, incluindo-se, entre outras, aquelas relativas aos enfrentamentos armados com os guerrilheiros, à captura e detenção dos civis com vida, ao recolhimento de corpos de guerrilheiros mortos, aos procedimentos de identificação dos guerrilheiros mortos quaisquer que sejam eles, incluindo-se as averiguações dos técnicos/peritos, médicos ou não, que desses procedimentos tenham participado, as informações relativas ao destino dado a esses corpos e todas as informações relativas à transferência de civis vivos ou mortos para quaisquer áreas. ${ }^{24}$

A União apresentou recurso contra esta decisão, como previsível. Em novembro de 2004, o Tribunal Regional Federal confirmou a decisão da juíza Salgado e marcou uma audiência com as partes envolvidas para implementar tal decisão. A União recorreu novamente, argumentando que a referida decisão deveria ser executada no foro de origem da ação. Em 26 de junho de 2007, o Superior Tribunal de Justiça (STJ), ao mesmo tempo que confirmou a sentença de Salgado, deu provimento ao recurso da União, ordenando que o foro de origem executasse a dita sentença.

Em outubro de 2003, enquanto o recurso ainda tramitava no Tribunal Regional Federal, o Presidente Lula criou uma Comissão Interministerial com o objetivo de obter informações sobre os corpos dos desaparecidos durante o massacre da Guerrilha do Araguaia (Decreto 4.850/2003). É importante destacar que, diferentemente da Comissão Especial sobre Mortos e Desaparecidos Políticos, esta Comissão Interministerial foi constituída apenas por representantes do Estado.

Embora a decisão da juíza Solange Salgado tivesse dado nova visibilidade ao caso da Guerrilha do Araguaia, tendo sido amplamente divulgada pelos meios de comunicação, a mobilização do caso perante a CIDH estava

${ }^{24}$ Processo no $^{\circ}$-44/82-B, renumerado como Processo no ${ }^{\circ}-108 / 83,1^{a}$ Vara da Justiça Federal do Distrito Federal. 
paralisada desde a publicação do relatório de admissibilidade em 2001. Os recursos interpostos pela União protelaram o término da disputa judicial e frustraram a CFMDP e o GTNM-RJ, que se queixavam da morosidade da justiça nacional e internacional. O CEJIL, no entanto, via-se diante de um impasse: mobilizar o caso para que a CIDH decidisse sobre o mérito e publicasse o relatório final, ou criar uma nova estratégia para que a $\mathrm{CIDH}$ encaminhasse o caso à Corte? Este impasse fez com que a tramitação e mobilização do caso ficasse em estado de dormência por algum tempo. Em meados de 2006, entrevistei uma das advogadas da assessoria internacional da SEDH, cuja função é acompanhar os casos contra o Brasil na CIDH, que declarou o seguinte:

O impacto que o caso da Guerrilha do Araguaia tem nas negociações, nas ações do governo é zero. Então, do ponto de vista da tramitação internacional, esse caso anda parado faz algum tempo, não há movimentação nenhuma. Eu não me lembro de ter feito, de ter escrito alguma coisa sobre esse caso desde que eu estou aqui [2002]. ${ }^{25}$

Em março de 2007, a Comissão Interministerial apresentou o seu relatório final, afirmando, entre outras coisas, que o Exército brasileiro continuava a declarar que todos os documentos relacionados à Guerrilha do Araguaia haviam sido destruídos. O relatório também deixou claro que a referida comissão trabalhou sob a condição, exigida pelos militares, de não usar a informação solicitada ao Exército para revisar a Lei de Anistia. O relatório informou que, na busca de informações sobre as circunstâncias das mortes e desaparecimentos políticos na Guerrilha do Araguaia, a Comissão Interministerial não tornaria necessariamente públicos os nomes dos oficiais ou agentes do Estado que praticaram violações de direitos humanos. Apesar de reconhecer a sua responsabilidade com relação aos crimes cometidos pelos órgãos de repressão no passado, o governo federal aceitou, assim, as condições estabelecidas pelos militares, numa clara evidência da ambigüidade e contradição da atuação do governo.

\subsection{A ressignificação do caso no contexto da globalização e normalização do paradigma de justiça de transição}

Graças às novas mobilizações da CFMDP, do GTNM/RJ e dos seus aliados, os anos de 2005 a 2008 foram importantes por trazerem ao centro dos debates públicos o direito à informação, a revisão da lei sobre a abertura

\footnotetext{
${ }^{25}$ Entrevista com Renata Pelisan, assessora internacional da SEDH, concedida à autora em Brasília, em 22 de agosto de 2006.
} 
dos arquivos e a questão da responsabilidade dos agentes do Estado pelos crimes praticados durante a ditadura. O tema da interpretação da Lei de Anistia passou a ocupar um lugar de destaque nesses debates. ${ }^{26}$

Em 2005, a família de Maria Amélia de Almeida Teles ajuizou uma ação declaratória para o reconhecimento das torturas sofridas por seus membros no DOI-CODI de São Paulo, sob o comando do coronel Carlos Alberto Brilhante Ustra no início dos anos 70. No âmbito da justiça transnacional, ao mesmo tempo em que o caso da Guerrilha do Araguaia apresentado à $\mathrm{CIDH}$ ainda aguardava uma decisão sobre o mérito, a Corte Interamericana de Direitos Humanos consolidava a sua jurisprudência sobre a inadmissibilidade das leis de "auto-anistia", com as sentenças proferidas em 2006 no caso Almonacid e Outros c. Chile, relativo ao regime Pinochet, e no caso do massacre na Universidade de La Cantuta, relativo ao Peru. Em 2008, esta jurisprudência serviu de base à fundamentação da sentença proferida em favor da família Teles na ação declaratória contra o coronel Ustra.

Contrariando, porém, a jurisprudência da Corte Interamericana de Direitos Humanos, a Advocacia Geral da União (AGU) emitiu, em 2008, um parecer a favor de uma ampla interpretação da Lei de Anistia de 1979, para contemplar os crimes cometidos pelos agentes do Estado durante a ditadura. O parecer provocou a paralisação da Ação Civil Pública interposta pelo Ministério Público Federal em São Paulo para apurar a responsabilidade de dois oficiais do Exército (um deles sendo o coronel Ustra), acusados de haverem determinado a prática de tortura, prisão ilegal, assassinato e desaparecimento forçado de diversas pessoas durante a ditadura. A SEDH e o Ministério da Justiça reagiram contra o parecer da AGU. Promoveram, em meados de 2008, a audiência pública sobre "Limites e Possibilidades para a Responsabilização Jurídica dos Agentes Violadores de Direitos Humanos durante o Estado de Exceção no Brasil”, na qual se discutiu a interpretação da Lei de Anistia de 1979. O Conselho Federal da Ordem dos Advogados do Brasil (OAB) também reagiu contra o parecer da AGU e ajuizou uma ação de Arguição de Descumprimento de Preceito Fundamental (ADPF 153) perante o Supremo Tribunal Federal (STF), requerendo o posicionamento deste tribunal acerca da aplicação da Lei de Anistia de 1979 aos agentes do Estado que praticaram torturas durante a ditadura.

Aproveitando a efervescência dos debates no Brasil sobre o escopo e os limites da Lei de Anistia, o CEJIL realizou, em 2008, a Audiência Temática

${ }^{26}$ Ver o site http://www.desaparecidospoliticos.org.br/, criado pela CFMDP, bem como o site http://www.torturanuncamais-rj.org.br/, criado pelo GTNM-RJ. 
intitulada "A Lei de Anistia como Obstáculo à Justiça no Brasil", na sede da CIDH, em Washington. Um dos objetivos desta audiência era produzir novas informações para influenciar a decisão que se esperava da CIDH sobre o caso da Guerrilha do Araguaia. ${ }^{27}$

Em março de 2009, a CIDH encaminhou o caso à Corte Interamericana de Direitos Humanos, criando, assim, uma maior pressão política sobre o governo brasileiro. A descrição do caso no comunicado de imprensa da CIDH de 8 de abril de 2009 mostra uma nítida ampliação do enfoque da disputa judicial iniciada em 1982 nos tribunais nacionais e levada à CIDH em 1995:

O caso está relacionado à detenção arbitrária, tortura e desaparecimento forçado de 70 pessoas, entre membros do Partido Comunista do Brasil e camponeses da região [...]. Do mesmo modo, relaciona-se com a Lei de Anistia (Lei No. 6.683/79). [...] Além disso, o caso trata sobre a figura do sigilo permanente de arquivos oficiais $\left[\ldots . .{ }^{28}\right.$

Verifica-se, assim, que a mobilização jurídica transnacional é utilizada para reconstruir a memória política e para pressionar o Estado a realizar um trabalho de justiça-memória nos parâmetros do paradigma globalizado e normalizado da justiça de transição.

\section{Considerações finais}

Como mostra o caso da Guerrilha do Araguaia, a mobilização jurídica transnacional desempenha um papel importante, porém limitado, no trabalho de justiça-memória, que é sempre seletivo e marcado por relações de poder. $\mathrm{Na}$ tramitação do caso da Guerrilha do Araguaia, a atuação do Estado e as suas políticas de "justiça de transição" revelam-se ambíguas e contraditórias. O Estado brasileiro resiste em reconhecer a sua responsabilidade e em permitir, quer no contexto da ditadura, quer no período democrático, o completo acesso a informações que possam esclarecer os crimes cometidos pelos órgãos oficiais de repressão no passado recente. O caso da Guerrilha do Araguaia sugere, assim, que novas democracias, como a brasileira, não rompem necessariamente com as estruturas de poder que davam sustentação ao regime anterior; tampouco transformam simultaneamente as culturas jurídicas de todos os setores do Estado e da sociedade. Este caso convida, portanto, a uma abordagem crítica da justiça de transição, que

\footnotetext{
${ }^{27}$ Ver http://www.ibccrim.org.br/site/noticias/conteudo.php?not_id=13182, acedido em 25 de novembro de 2008.

${ }^{28}$ Ver http://www.cidh.oas.org/Comunicados/Port/16.09port.htm, acedido em 11 de abril de 2009.
} 
problematize a capacidade do Estado e do seu sistema de justiça em promover o trabalho da justiça-memória.

A tramitação do caso da Guerrilha do Araguaia, desde os tribunais nacionais até a CIDH e a Corte Interamericana de Direitos Humanos, mostra um percurso de mobilização jurídica dos direitos humanos que se vai utilizando das oportunidades políticas e jurídicas disponíveis para (re)formular, dentro das limitações de cada contexto político, o significado e o alcance do objeto da disputa judicial de acordo com os múltiplos e por vezes conflitantes interesses dos peticionários.

O uso do direito serve, assim, para reconstruir a memória política. A contínua (re)formulação do objeto da disputa implica uma constante reconstrução da própria memória política. No caso da Guerrilha do Araguaia, as pretensões dos autores dizem respeito, entre outras coisas, ao resgate da história e da memória dos mortos e desaparecidos políticos e da tortura que estes sofreram. Na tramitação do caso, os fatos são selecionados e reinterpretados pelas partes e pelos juízes (ou comissionados, em se tratando da $\mathrm{CIDH}$ ); os juízes declaram a verdade dos fatos sob a forma de "verdades jurídicas" e atribuem, ou não, responsabilidades e sanções, que podem, ou não, ser executadas; as partes vão produzindo novas provas; e o desenrolar da disputa judicial ou quasi-judicial - que se estende dos tribunais para a política, e vice-versa - contribui para a reconstrução da memória política. A morosidade da justiça pode aqui ser vista como uma oportunidade para reavivar a memória que, pela via judicial subsidiária à mobilização política, se reconstitui em um presente contínuo de mobilização dos direitos humanos. Nesta perspectiva, a morosidade da justiça, embora negando a prestação da justiça, pode ser utilizada estrategicamente para redirecionar a mobilização do direito e redefinir o objeto da disputa jurídica e política.

A mobilização jurídica, quer em escala nacional, quer em escala transnacional, apresenta, porém, algumas limitações. Depende, em grande medida, das condições políticas e sociais locais e internacionais. Há custos econômicos, sociais e emocionais para os autores, que ficam com o fardo do ônus da prova. O Estado nem sempre exerce o seu "dever de memória" (Todorov, 2004). Os tempos dos processos judiciais não coincidem com os tempos das lutas sociais e políticas. E a morosidade das instituições judiciais e quasi-judiciais torna-se, nessa perspectiva, um obstáculo para o estabelecimento de medidas de justiça.

Tanto o governo Cardoso como o governo Lula promulgaram decretos, medidas provisórias e leis que estenderam, indefinidamente, o prazo para tornar públicos os documentos oficiais considerados "de mais alto grau de sigilo". Ao mesmo tempo, criaram e/ou fortaleceram a SEDH, a Comissão 
Especial sobre Mortos e Desaparecidos Políticos e a Comissão de Anistia, que têm envidado esforços no estabelecimento de medidas administrativas e reparatórias de "justiça de transição". Em 2007, a SEDH e a Comissão Especial sobre Mortos e Desaparecidos Políticos lançaram o livro-relatório Direito à Memória e à Justiça, ${ }^{29}$ onde o governo reconheceu a responsabilidade dos órgãos de repressão pelos crimes da ditadura. Mas, além de limitadas as atribuições da SEDH e das comissões de reparação, grupos de familiares de "mortos e desaparecidos políticos" alegavam que nenhum governo pós-ditadura criou uma "Comissão de Verdade" (Lisbôa, 2007). Esta ideia tornou-se uma proposta política concreta a partir do lançamento, no final de 2009, do $3^{\circ}$ Plano Nacional dos Direitos Humanos.

O Estado brasileiro encontra-se, no entanto, internamente dividido no que se refere a medidas de "justiça de transição". Em 29 de abril de 2010, o Supremo Tribunal Federal decidiu, por 7 votos contra 2, pela improcedência da ação de Arguição de Descumprimento de Preceito Fundamental (ADPF 153) ajuizada pela Ordem dos Advogados do Brasil, mantendo, assim, uma interpretação ampla da Lei de Anistia e sua aplicação aos agentes do Estado que praticaram torturas durante a ditadura militar. Em contrapartida, o Presidente Lula encaminhou um projeto de lei ao Congresso para a criação de uma "Comissão Nacional da Verdade". A Corte Interamericana de Direitos Humanos realizou, por sua vez, uma audiência em maio de 2010 para ouvir as partes envolvidas no caso da Guerrilha do Araguaia.

Ainda que a existência dos arquivos das Forças Armadas seja negada pelos militares, o trabalho de justiça-memória da ditadura seguirá o seu curso. As fontes da memória e da justiça vão além dos documentos e rastros de práticas de tortura possivelmente apagados pelas Forças Armadas. Embora o número oficial de "mortos e desaparecidos políticos" no Brasil seja muito pequeno (cerca de 400), a SEDH (2010: 173) indica que "pelo menos 50 mil pessoas foram presas nos primeiros anos de 1964" e "cerca de 20 mil brasileiros foram submetidos a torturas". Um amplo e aprofundado trabalho de justiça-memória em relação a este passado recente de violência política praticada pelo Estado faz-se ainda necessário no Brasil.

Diante da possibilidade de criação de uma "Comissão Nacional da Verdade", alguns desafios que, a meu ver, se colocam dizem respeito ao seu processo de constituição e ao modo, mais ou menos democrático, com que administrará a justiça e representará a pluralidade de sujeitos jurídicos e

\footnotetext{
${ }^{29}$ O livro foi organizado pela Comissão Especial sobre Mortos e Desaparecidos Políticos (CEMDP), constituída pela Lei 9.140/1995. Este documento oficial de memória baseou-se, amplamente, no Dossiê dos Mortos e Desaparecidos Políticos a partir de 1964, organizado por familiares de mortos e desaparecidos políticos, cuja primeira edição foi publicada em 1995.
} 
políticos de memória. Além disso, será preciso conectar a violência da ditadura e de outros períodos na história do Brasil com as persistentes e graves violações de direitos humanos que continuam a ser objeto de denúncia junto à Comissão Interamericana de Direitos Humanos e que refletem as estruturas sociais que fazem parte da formação política e jurídica dominante no Brasil.

\section{Referências bibliográficas}

Affonso, Beatriz; Freund, Rita Lamy (2005), "Efeitos práticos das decisões dos órgãos do sistema interamericano de direitos humanos”, in Evanize Sydow; Maria Luisa Mendonça (orgs.), Direitos humanos no Brasil - Relatório da Rede Social de Justiça e Direitos Humanos. São Paulo: Rede Social de Justiça e Direitos Humanos (http://www.social. org.br/relatorio2005/relatorio035.htm, acessado em 24 de abril de 2007).

Arquidiocese de São Paulo (2003), Brasil: nunca mais. São Paulo: Editora Vozes [33ª ed.].

Bilsky, L. (2007), Transformative Justice: Israeli Identity on Trial. Ann Arbor, MI: University of Michigan Press.

Booth, W. James (2006), Communities of Memory: On Witness, Identity, and Justice. Ithaca: Cornell University Press.

Brasil. Secretaria Especial dos Direitos Humanos da Presidência da República (2010), Programa Nacional de Direitos Humanos (PNDH 3). Brasília: Secretaria Especial dos Direitos Humanos da Presidência da República.

Cavallaro, James L.; Brewer, Stephanie Erin (2008), "O papel da litigância para a justiça social no Sistema Interamericano", Sur - Revista Internacional de Direitos Humanos, 5(8), 85-98.

Cavallaro, James L. (2002), "Toward Fair Play: A Decade of Transformation and Resistance in International Human Rights Advocacy in Brazil", Chicago Journal of International Law, 3(2): 481-492.

Comissão de Familiares de Mortos e Desaparecidos Políticos; Instituto de Estudos sobre a Violência do Estado (IEVE); Grupo Tortura Nunca Mais do Rio de Janeiro e de São Paulo (2001), "Mortos e desaparecidos políticos: um resgate da memória brasileira", in Janaína Teles (org.), Mortos e Desaparecidos Políticos: reparação ou impunidade? São Paulo: Humanitas/FFLCH/USP, 157-198 [2ª ed.].

Comissão Especial sobre Mortos e Desaparecidos Políticos (2007), Direito à Verdade e à Memória. Brasília: Secretaria Especial dos Direitos Humanos.

Di Paolantonio, Mario (2004), "Tracking the Transitional Demand for Legal Recall: The Foreclosing and Promise of Law in Argentina”, Social Legal Studies, 13(3), 351-375.

Douglas, Lawrence (2001), The Memory of Judgment: Making Law and History in the Trials of the Holocaust. London: Yale UP. 
Duthie, Roger (2008), “Toward a Development-sensitive Approach to Transitional justice”, The International Journal of Transitional Justice, 2, 292-309.

Hanashiro, Olaya Sílvia Machado (2001), O Sistema Interamericano de Proteção aos Direitos Humanos. São Paulo: Editora da Universidade de São Paulo/FAPESP. Jelin, Elizabeth (2003), State Repression and the Labors of Memory. Minneapolis: University of Minnesota Press.

Junqueira, Eliane B. (1996), “Acesso à justiça: um olhar retrospectivo”, Revista Estudos Históricos, 18, 1-15.

Keck, Margaret E.; Sikkink, Kathryn (1998), Activists beyond Borders: Advocacy Networks in International Politics. Ithaca and London: Cornell UP.

Lisbôa, Suzana Keniger (2007), "Direito à memória e à verdade”, in Evanize Sydow; Maria Luisa Mendonça (orgs.), Direitos Humanos no Brasil - Relatório da Rede Social de Justiça e Direitos Humanos. São Paulo: Rede Social de Justiça e Direitos Humanos, 185-188.

Lundy, Patricia; McGovern, Mark (2008), “The Role of Community in Participatory Transitional Justice”, in Kieran McEvoy; Lorna McGregor (orgs.), Transitional Justice from Below: Grassroots Activism and the Struggle for Change. Oxford and Portland, Oregon: Hart Publishing, 99-120.

Markovits, Inga (2001), "Selective Memory: How the Law Affects What We Remember and Forget about the Past - The Case of East Germany", Law and Society Review, 35(3): 513-563.

McAdams, A. James (org.) (2001), Transitional Justice and the Rule of Law in New Democracies. Notre Dame: University of Notre Dame Press.

McEvoy, Kieran (2008), "Letting go of Legalism: Developing a 'Thicker' Version of Transitional Justice”, in Kieran McEvoy; Lorna McGregor (orgs.), Transitional Justice from Below: Grassroots Activism and the Struggle for Change. Oxford and Portland, Oregon: Hart Publishing, 15-45.

McEvoy, Kieran; McGregor, Lorna (2008), "Transitional Justice from Below: An Agenda for Research, Policy and Praxis”, in Kieran McEvoy; Lorna McGregor (orgs.), Transitional Justice from Below: Grassroots Activism and the Struggle for Change. Oxford and Portland, Oregon: Hart Publishing, 1-13.

Méndez, Juan E. (2001), "In Defense of Transitional Justice”, in A. James McAdams (org.), Transitional Justice and the Rule of Law in New Democracies. Notre Dame: University of Notre Dame Press, 1-26 [2 ${ }^{\mathrm{a}}$ ed.; ${ }^{1} 1997$ ].

Mezarobba, Glenda (2009), “Anistia de 1979: o que restou da lei forjada pelo arbítrio?”, in Cecília MacDowell Santos; Edson Teles; Janaína de Almeida Teles (orgs.), Desarquivando a ditadura: memória e justiça no Brasil. São Paulo: Editora Hucitec, 372-384.

Mihai, Mihaela (2009), Transitional Justice and the Quest for Democracy: Towards a Political Theory of Democratic Transformations. Dissertação (Doutorado em Ciência Política) - Departamento de Ciência Política, Universidade de Toronto, Toronto. 
Minow, Martha (2002), "Memory and Hate: Are there Lessons from Around the World?”, in Nancy Rosenblum (org.), Breaking the Cycles of Hatred: Memory, Law, and Repair. Princeton: Princeton University Press, 15-30.

Misztal, Barbara A. (2005), "Memory and Democracy", American Behavioral Scientist, 48(10), 1320-1338.

Moraes, Mário Sérgio de (2006), O Caso da Ditadura. Caso Herzog. São Paulo: Editora Barcarolla.

Osiel, Mark (1997), Mass Atrocity, Collective Memory, and the Law. New Brunswick: Transaction Publishers.

Pereira Neto, Murilo Leal (2009), "Sidney, Olavo e Jeremias”, in Cecília MacDowell Santos; Edson Teles; Janaína de Almeida Teles (orgs.), Desarquivando a ditadura: memória e justiça no Brasil. São Paulo: Editora Hucitec, 25-46.

Piovesan, Flávia (2006), “A advocacia do direito internacional dos direitos humanos: casos contra o Estado brasileiro perante a Comissão Interamericana de Direitos Humanos", in Flávia Piovesan, Direitos Humanos e o Direito Constitucional Internacional. São Paulo: Editora Saraiva, 277-314 [7 ed.].

Rose, Cecily; Ssekandi, Francis M. (2007), “The Pursuit of Transitional Justice and African Traditional Values: A Clash of Civilizations - The Case of Uganda", Sur - International Journal on Human Rights, 4(7), 101-125.

Rosenblum, Nancy (2002), "Introduction: Memory, Law and Repair”, in Nancy Rosenblum (org.), Breaking the Cycles of Hatred: Memory, Law, and Repair. Princeton: Princeton UP, 1-13.

Santos, Boaventura de Sousa; Rodríguez-Garavito, César A. (orgs.) (2005), Law and Globalization from Below: Towards a Cosmopolitan Legality. Cambridge: Cambridge UP.

Santos, Cecília MacDowell (2007), "Transnational Legal Activism and the State: Reflections on Cases against Brazil in the Inter-American Commission on Human Rights", Sur - International Journal on Human Rights, 4(7), 29-59.

Santos, Cecília MacDowell (2009), "A justiça ao serviço da memória: mobilização jurídica transnacional, direitos humanos e memória da ditadura”, in Cecília MacDowell Santos; Edson Teles; Janaína de Almeida Teles (orgs.), Desarquivando a ditadura: memória e justiça no Brasil. São Paulo: Editora Hucitec, 472-495.

Soares, Samuel Alves; Prado, Larissa Brisola Brito (2009), "O processo político da anistia e os espaços da autonomia militar”, in Cecília MacDowell Santos; Edson Teles; Janaína de Almeida Teles (orgs.), Desarquivando a ditadura: memória e justiça no Brasil. São Paulo: Editora Hucitec, 353-371.

Teitel, Ruti G. (2000), Transitional Justice. New York: Oxford UP.

Teitel, Ruti (2003), “Transitional Justice Genealogy”, Harvard Human Rights Journal, 16, 69-94.

Teles, Janaína de Almeida (2005), Os herdeiros da memória. A luta dos familiares de mortos e desaparecidos políticos por verdade e justiça no Brasil. Dissertação (Mestrado 
em História) - Faculdade de Filosofia, Letras e Ciências Humanas, Universidade de São Paulo, São Paulo.

Teles, Janaína de Almeida (org.) (2001), Mortos e desaparecidos políticos: reparação ou impunidade? São Paulo, Humanitas/FFLCH/USP [2a ed.].

Todorov, Tzvetan (2004), Les abus de la mémoire. Paris: Arléa [2 2 a ed.; $\left.{ }^{1} 1995\right]$.

Urs, Tara (2007), "Imagining Locally-motivated Accountability for Mass Atrocities: Voices from Cambodia”, Sur - International Journal on Human Rights, 4(7), 61-99. Vasconcelos, Daniela Mateus de (2009), "Memória política, democracia e accountability: algumas reflexões teóricas”, Oficina do CES, 330. 